\title{
Consistency between hydrological model, large aperture scintillometer and remote sensing based evapotranspiration estimates for a heterogeneous catchment
}

\author{
B. Samain ${ }^{1}$, G. W. H. Simons ${ }^{2}$, M. P. Voogt ${ }^{2}$, W. Defloor ${ }^{3}$, N.-J. Bink ${ }^{4}$, and V. R. N. Pauwels ${ }^{1}$ \\ ${ }^{1}$ Laboratory of Hydrology and Water Management, Ghent University, Ghent, Belgium \\ ${ }^{2}$ WaterWatch, Wageningen, The Netherlands \\ ${ }^{3}$ Flemish Environmental Agency, Department Operational Water Management, Brussels, Belgium \\ ${ }^{4}$ Wittich and Visser, Rijswijk, The Netherlands
}

Correspondence to: B. Samain (bruno.samain@ugent.be)

Received: 17 November 2011 - Published in Hydrol. Earth Syst. Sci. Discuss.: 9 December 2011

Revised: 18 June 2012 - Accepted: 19 June 2012 - Published: 13 July 2012

\begin{abstract}
The catchment averaged actual evapotranspiration rate is a hydrologic model variable that is difficult to quantify. Evapotranspiration rates - up till present - cannot be continuously observed at the catchment scale.

The objective of this paper is to estimate the evapotranspiration rates (or its energy equivalent, the latent heat fluxes LE) for a heterogeneous catchment of $102.3 \mathrm{~km}^{2}$ in Belgium using three fundamentally different algorithms.

One possible manner to observe this variable could be the continuous measurement of sensible heat fluxes $(H)$ across large distances (in the order of kilometers) using a large aperture scintillometer (LAS), and converting these observations into evapotranspiration rates. Latent heat fluxes are obtained through the energy balance equation using a series of sensible heat fluxes measured with a LAS over a distance of $9.5 \mathrm{~km}$ in the catchment, and point measurements of net radiation $\left(R_{\mathrm{n}}\right)$ and ground heat flux $(G)$ upscaled to catchment average through the use of TOPLATS, a physically based land surface model.

The resulting LE-values are then compared to results from the remote sensing based surface energy balance algorithm ETLook and the land surface model. Firstly, the performance of ETLook for the energy balance terms has been assessed at the point scale and at the catchment scale. Secondly, consistency between daily evapotranspiration rates from ETLook, TOPLATS and LAS is shown.
\end{abstract}

\section{Introduction}

Evapotranspiration (ET) estimates are needed for a wide range of problems in hydrology, agronomy, forestry and land management, and water resources planning, such as water balance computation, river flow forecasting, ecosystem modeling, etc. Due to complex interactions amongst the components of the land-plant-atmosphere system, evapotranspiration is perhaps the most difficult of all the components of the hydrologic cycle to assess (Xu and Singh, 2005).

Most methods for the estimation of evapotranspiration rates are point-scale approaches. Estimates at large spatial scales can be obtained using remote sensing and spatially distributed hydrological models. For large scale assessment of ET, extended networks of (field) sensors have a large potential for ET estimation. However, typically, regional to continental scale information on ET is obtained with the application of Earth observation techniques, although thermal and optical techniques require clear sky imagery (Verstraeten et al., 2008), which limits these techniques for the continuous observation of ET.

The scintillation method is an attractive method for routinely observing the surface fluxes across large distances (Meijninger et al., 2002). For evapotranspiration (or its energy equivalent, latent heat flux LE) measurements, scintillometers operating at radio wave lengths are best suited, but

Published by Copernicus Publications on behalf of the European Geosciences Union. 
for a variety of reasons (expensive technology, complexity, absorption effects, and required licenses), these are not yet commercially available (Meijninger et al., 2006). At present, optical scintillometers are more widely used, but they can only estimate the sensible heat flux across a large distance.

A number of studies have already focused on estimation of evapotranspiration rates (or LE) from sensible heat flux measurements acquired from LAS-data. In all of these studies, the latent heat flux is always estimated as the rest-term of the energy balance ( $\mathrm{LE}=R_{\mathrm{n}}-G-H$ ). So, the estimation of a representative value for the available energy $\left(\mathrm{AE}=R_{\mathrm{n}}-G\right)$ is always crucial for the accuracy of the retrieved values of LE. For short scintillometer paths over a homogeneous surface, Pauwels and Samson (2006) and Savage (2009) showed that the latent heat flux as rest-term of the energy balance where $H$ is measured by a scintillometer and $R_{\mathrm{n}}$ and $G$ are measured at a point location along the scintillometer path, resulted in a good agreement between the LAS-derived latent heat fluxes and LE as measured with Bowen Ratio Energy Balance (BREB) and Eddy Covariance (EC) - stations along the path. The same method was used for larger and more hetereogeneous areas by Ezzahar and Chehbouni (2009) and Bai et al. (2009) who used the $H$ from a scintillometer measuring over a distance of about $1 \mathrm{~km}$ and $2.5 \mathrm{~km}$ respectively, combined with point measurements of $R_{\mathrm{n}}$ and $G$ within the scintillometer path to calculate the area averaged sensible heat flux. Hemakumara et al. (2003) estimated the latent heat flux on a daily basis $(24 \mathrm{~h}$ ) from LAS-measured $H$-fluxes over an almost $2 \mathrm{~km}$ path length with mixed land cover and point-measurements of $R_{\mathrm{n}}$. Because LE was estimated on a daily basis, the soil heat storage was assumed to be minimal, and $\mathrm{LE}_{24 \mathrm{~h}}$ has been calculated from $R_{\mathrm{n}, 24 \mathrm{~h}}$ and $H_{24 \mathrm{~h}}$ with promising results in a comparison with results from a remote sensing based surface energy balance algorithm. Guyot et al. (2009) calculated the spatially averaged latent heat flux for a small $\left(12 \mathrm{~km}^{2}\right)$ heterogeneous catchment in West Africa (Northern Benin) as the residual term of the energy balance equation where $H$ was measured with a scintillometer over the catchment, using point measurements of $R_{\mathrm{n}}$ which were shown to be representative for the heterogeneous catchment in wet conditions, and aggregated values of $G$ which were obtained as a simple average of local $G$-estimations based on soil temperature measurements at three different locations within the catchment. Ezzahar et al. (2009) derived the areaaveraged latent heat flux as the residual term of the energy balance equation through the combination of the LAS measurements over a $3.2 \mathrm{~km}$ slanted, heterogeneous path, and an aggregation scheme to derive area-average available energy based on the local measurements of the surface temperature, the albedo and the incoming solar radiation, all measured over the three different vegetation types. From all of these studies, it was concluded that a LAS is an adapted device to estimate the actual evapotranspiration through an energy balance approach at the catchment scale if the available energy
$\left(R_{\mathrm{n}}-G\right)$ is carefully estimated, so it can be assumed representative for the considered area.

Typically, evaluation of scintillometer measured $H$ and derived LE fluxes is performed by comparison with the measurements of an EC (Eddy Covariance) or BREB (Bowen Ratio Energy Balance) station. For homogeneous land cover along the scintillometer path (e.g. Pauwels and Samson, 2006; Savage, 2009), these can be assumed to be representative for the entire path. For more heterogeneous conditions (e.g. Ezzahar et al., 2009; Guyot et al., 2009; Bai et al., 2009), a weighted average from EC or BREB observations on different land cover types under the path is made, or a footprint analysis of the scintillometer signal is performed to determine which EC or BREB observations need to be assigned which weight in the aggregation scheme. However, sensible and latent heat fluxes do not only depend on the land cover type, but also on the soil moisture conditions, which can show a high spatial variability. So, in strongly hetereogeneous areas at large spatial scales, the evaluation approach based on one or more point measurements becomes infeasible (Samain et al., 2011). Alternative evaluation procedures for LAS-measurements over heterogeneous areas are described by Kleissl et al. (2008, 2009b), who intercompared different scintillometers over the same area. Models can also be used, as for example Ezzahar and Chehbouni (2009), who used a two-source energy-balance model, and Samain et al. (2011) who used a spatially distributed physically based land surface model. Another alternative for the evaluation of a LAS measurement is through the use of remote sensing data as performed by Hemakumara et al. (2003) and Kleissl et al. (2009a). Hemakumara et al. (2003) used the remote sensing based surface energy balance algorithm for land (SEBAL, Bastiaanssen et al., 1998) and NOAA satellite images to evaluate the LAS-derived ET-values and found that the average deviation of ET estimates between SEBAL and LAS for five 10-day periods was $17 \%$ and that this deviation fell to $1 \%$ when monthly estimates were considered. Kleissl et al. (2009a) have shown that SEBAL results generally agree with the 10-min-averaged surface LAS measurements at the overpass time at six sites and for four satellite overpasses in 2006. Although both studies indicate that the use of remote sensing data is a good evaluation tool for flux measurements over a large and heterogeneous area (as can be done with a scintillometer), the used remote sensing techniques are restricted by cloud coverage (Hemakumara et al., 2003) and only the instanteneous moments of satellite overpass can be evaluated (Kleissl et al., 2009a).

Recently, Samain et al. (2011) used a large aperture scintillometer (LAS), installed across a distance of $9.5 \mathrm{~km}$, to estimate the spatially averaged sensible heat flux for the $102.3 \mathrm{~km}^{2}$ heterogeneous Bellebeek catchment in Belgium. Through the use of a spatially distributed land surface model and a footprint analysis, they showed that the measurements of this LAS in unstable (daytime) conditions are representative for the entire catchment. In a next step, different 
algorithms have been evaluated to produce a continuous series (including stable conditions) of $H$ from the LAS data (Samain et al., 2012).

The main goal of this study is to explore the consistency for evapotranspiration estimates over a large, heterogeneous area between three fundamentally different techniques: the LAS-based values of actual evapotranspiration using LAS$H$ and the energy balance approach, the land surface model TOPLATS, and the remote sensing algorithm ETLook that is developed to calculate ET for lower temporal resolutions (daily time step).

A first objective of this paper is to make continuous series of hourly actual evapotranspiration rates for the Bellebeek catchment based on LAS measurements and the energy balance approach. This continuous catchment averaged actual ET-series can then, for example, be used as model forcing for rainfall-runoff models or for the validation of land surface and weather prediction models. Therefore, the continuous series of $H$ based on the LAS-data is used in combination with areally representative values of available energy $\left(<\mathrm{AE}>=<R_{\mathrm{n}}-G>\right)$. The estimates of $<\mathrm{AE}>$ are based on local measurements of $R_{\mathrm{n}}$ and $G$ which have been compared and upscaled for the heterogeneous catchment through the use of the calibrated spatially distributed physically based land surface model as described in and applied by Samain et al. (2011). This results in an operationally applicable technique for the estimation of catchment averaged actual evapotranspiration rates through the combination of only three measurements ( $H$ from LAS, and locally measured, but upscaled values for $\left.<\mathrm{AE}>=<R_{\mathrm{n}}-G\right\rangle$ ).

The second objective is to evaluate the consistency of the LAS-derived series of evapotranspiration rates on a daily basis for a period of six months through comparison with the results of ETLook, an algorithm based on remote sensing data to compute continuous daily evapotranspiration rates for large areas. Before checking the consistency between LASand ETLook-results, the performance of ETLook is evaluated by comparing ETLook-results to point-measurements and to catchment averaged fluxes modeled with the land surface model.

\section{Site and data description}

\subsection{Site description}

The study was performed in the Dender catchment in Belgium. Figure 1 shows the location of the catchment together with a Digital Elevation Model (DEM) of the area. A LAS was installed in the sub-catchment of the Bellebeek $\left(102.3 \mathrm{~km}^{2}\right)$. The elevation in the sub-catchment ranges between 10 and $110 \mathrm{~m}$. Soil texture is predominantly loam $(74 \%)$, and the land use is predominantly agriculture $(63.6 \%)$ and pasture $(22.9 \%)$. A total $8.6 \%$ of the surface consists of urban land cover and the remaining area consists of forest $(4.8 \%)$ and open water $(0.1 \%)$.

\subsection{Surface data sets}

Figure 1 shows the location of the meteorological station used in this study. Continuous measurements of wind speed and wind direction at $10 \mathrm{~m}$ height, as well as precipitation rates, air pressure, and air and dew point temperature at a height of $2 \mathrm{~m}$ were available at a 10-min interval from the meteorological station of Liedekerke, situated near the outlet of the catchment. Further, net radiation data from a NR-Lite net radiometer (Kipp and Zonen, Delft, The Netherlands) at $2 \mathrm{~m}$ height and ground heat flux observations from two HFP01 soil heat flux sensors (Hukseflux, Delft, The Netherlands) at $5 \mathrm{~cm}$ depth were also available at this site.

From 15 April 2009, an Eddy Covariance (EC) installation was installed at $2 \mathrm{~m}$ above the surface of a grassland in Ternat approximately in the middle of the scintillometerpath. The EC station consists of a 3-D sonic anemometer (CSAT3, Campbell Scientific Ltd.), and a Krypton hygrometer $\left(\mathrm{KH}_{2} \mathrm{O}\right.$, Campbell Scientific Ltd.). Raw data were sampled at a rate of $10 \mathrm{~Hz}$. The half-hourly fluxes were calculated off-line using the TK2 software package (Mauder and Foken, 2004; Mauder et al., 2008). With the TK2-package, the fluxes were calculated after despiking, cross wind correction, planar fit correction, correction of oxygen cross sensitivity for the Krypton hygrometer, correction of spectral loss, and correction for density fluctuations (WPL-correction, Webb et al., 1980). In combination with this EC-station, net radiation (NR-lite net radiometer) at $2 \mathrm{~m}$ above the surface and soil heat flux (two HFP01SC soil heat flux sensors) just below the surface were registered at a $10 \mathrm{~min}$ interval and were averaged to one hour intervals.

\subsection{Scintillometer data}

\subsubsection{Introduction}

The scintillometer used in this experiment is a large aperture scintillometer (LAS), type BLS2000 (Scintec AG, Tübingen, Germany). The transmitter is situated in Asse on a water tower at an elevation of $40 \mathrm{~m}$ above the surface. The receiver is installed in the church tower in Eizeringen at $15 \mathrm{~m}$ above the surface (Samain et al., 2011). The LAS measures over the sub-catchment of the Bellebeek along a $9.5 \mathrm{~km}$ path. This allows the beam to cross the basin well above the canopy, the small forests, the valley of the Bellebeek and its tributaries and roads and towns. According to Samain et al. (2011), the effective height $\left(z_{\text {eff }}, \mathrm{m}\right)$ of the beam is $68 \mathrm{~m}$, calculated following Hartogensis et al. (2003). The BLS2000 has an aperture size of $0.26 \mathrm{~m}$, suitable for flux-measurements on a relatively large spatial scale (up to $10 \mathrm{~km}$ ) without running into the problem of saturation of the LAS signal (Kohsiek et al., 2006). 


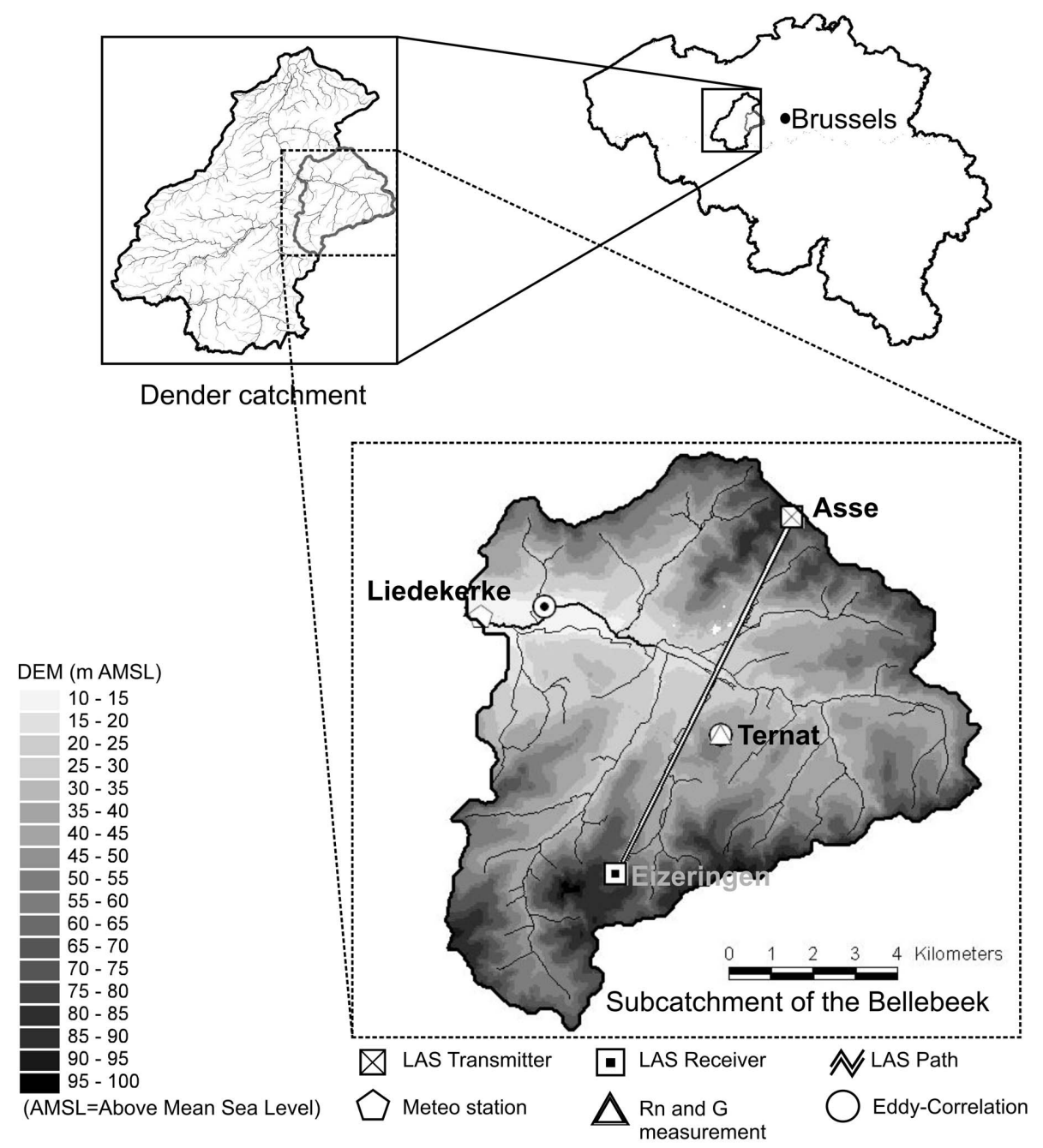

Fig. 1. The location of the study site in Belgium, a DEM of the study area and the location of the meteorologic stations and the LAS in the study area.

From the 1-min data of observed intensities, 1-min $H$ values are derived using the calculation procedure explained in Samain et al. (2011). From this procedure, obtaining the sensible heat flux from a scintillometer measurement over a heterogeneous area requires the measurement of a number of additional parameters (Table 1): air temperature, air pressure, Bowen ratio, zero-plane displacement height, and friction velocity representative for the area under the LAS. As shown in Samain et al. (2011), representative sensible heat fluxes for the heterogeneous catchment of the Bellebeek can be calculated from the LAS data at $68 \mathrm{~m}$ height in combination with the air temperature and air pressure from the meteorological station at Liedekerke, the zero-plane displacement height estimated as $0.7 \mathrm{~m}$ and the friction velocity calculated from the measured wind speed at the Liedekerke meteorological station. The 1-min values of $H$ are then averaged per hour. Samain et al. (2012) further describe the construction of an almost continuous series of hourly sensible heat fluxes using an operational algorithm based on the diurnal cycle of the refractive index structure parameter $C_{N}^{2}$ and by ignoring the humidity correction based on the Bowen ratio. This ignoring of the humidity correction has been shown to result in an increase of the completeness of the resulting $H$-series with only a marginal error in $H$. In this paper, the energy balance equation will be applied to calculate latent heat fluxes from these $H$-fluxes.

\subsubsection{Available time series from LAS}

The LAS in the Bellebeek catchment has been operational since 21 February 2008. For the present study, data from six months (from 1 April 2009 through 30 September 2009) are used. Unfortunately, due to logging problems, no LASdata were available for three periods within these six months: from 9 June 2009, through 2 July 2009, from 10 July 2009 through 14 July 2009, and from 16 September 2009 through 
Table 1. Input data for the three different techniques to calculate catchment averaged latent heat flux.

\begin{tabular}{|c|c|c|c|c|}
\hline Parameter & Source & LAS & TOPLATS & ETLook \\
\hline \multicolumn{5}{|c|}{ Temporal resolution: hourly or less } \\
\hline LAS-intensities & LAS & $\mathrm{X}$ & & \\
\hline air temperature & Liedekerke meteo-station & $\mathrm{X}$ & $\mathrm{X}$ & $\mathrm{X}$ \\
\hline air pressure & Liedekerke meteo-station & $X$ & & \\
\hline wind speed & Liedekerke meteo-station & $\mathrm{X}$ & & $\mathrm{X}$ \\
\hline precipitation & Liedekerke meteo-station & & $\mathrm{X}$ & $\mathrm{X}$ \\
\hline relative humidity & Liedekerke meteo-station & & $\mathrm{X}$ & $\mathrm{X}$ \\
\hline net radiation & Liedekerke meteo-station & $\mathrm{X}$ & $\mathrm{X}$ & \\
\hline soil heat flux & Liedekerke meteo-station & $\mathrm{X}$ & & \\
\hline \multicolumn{5}{|c|}{ Temporal resolution: daily or more } \\
\hline surface albedo (resolution $30 \mathrm{~m}$ ) & satellite images (DMC, Landsat, ASTER) & & & $\mathrm{X}$ \\
\hline Normalized Difference Vegetation Index (resolution 30 m) & satellite images (DMC, Landsat, ASTER) & & & $\mathrm{X}$ \\
\hline athmospheric transmissivity (resolution $6 \mathrm{~km}$ ) & Meteosat Second Generation & & & $\mathrm{X}$ \\
\hline \multicolumn{5}{|c|}{ Maps } \\
\hline Digital elevation model (DEM) (resolution $50 \mathrm{~m}$ ) & Flanders Geographical Information Agency & & $\mathrm{X}$ & \\
\hline Soil texture map (resolution $50 \mathrm{~m}$ ) & Flanders Geographical Information Agency & & $\mathrm{X}$ & \\
\hline Land cover map (resolution $50 \mathrm{~m}$ ) & Flanders Geographical Information Agency & & $\mathrm{X}$ & \\
\hline Land cover map (resolution $30 \mathrm{~m}$ ) & European Environment Agency & & & $\mathrm{X}$ \\
\hline \multicolumn{5}{|c|}{ Constants } \\
\hline effective height & based on DEM (68 m) & $\mathrm{X}$ & & \\
\hline zero-plane displacement height & estimate $(0.7 \mathrm{~m})$ & $\mathrm{X}$ & & \\
\hline surface roughness length & estimate $(0.3 \mathrm{~m})$ & $\mathrm{X}$ & & \\
\hline
\end{tabular}

20 September 2009. For this six months period (4392 hourly time steps), no LAS data are available for 755 time steps (or $17.2 \%$ of the time steps). Using the algorithm for constructing a continuous time series of $H$ from LAS, as explained by Samain et al. (2012), from the remaining 3637 time steps, a reliable estimate of $H$ could be obtained for 3100 time steps, which is an availability of approximately $85 \%$ of the available LAS-time steps. The loss of $15 \%$ of the data is because no reliable $H$ could be calculated because of precipitation $(7.2 \%)$ or because no reliable hourly $C_{N}^{2}$ was obtained from LAS-data $(1.3 \%)$ or the algorithm could not be applied $(6.3 \%)$, e.g. because no clear $C_{N}^{2}$-minimum could be found around the transition between different stability conditions.

\section{$3<$ LE $>$ from LAS}

A LAS provides the opportunity to provide surface fluxes of sensible heat across a distance of several kilometers and over a heterogeneous landscape. As shown by different authors, it is feasible to use the LAS for operationally estimating area-averaged $<\mathrm{LE}>$ as the residual term of the energy balance equation, providing estimates of area-average available energy $\left(<\mathrm{AE}>=<R_{\mathrm{n}}-G>\right.$ ) are available. Samain et al. (2011) have shown that the LAS measurements over a distance of $9.5 \mathrm{~km}$ and an effective height of $68 \mathrm{~m}$ are representative for the entire catchment of $102.3 \mathrm{~km}^{2}$. To calculate representative values for $\langle\mathrm{LE}\rangle$ from the energybalance approach, representative values for the available energy $<\mathrm{AE}>$ are required. $<\mathrm{AE}>$ could be constructed by deploying a network of net radiometers $\left(R_{\mathrm{n}}\right)$ and soil heat flux plates $(G)$ on the different land cover types and soil wetness conditions within the catchment. However, this approach is practically not feasible, not only because the considered catchment is very heterogeneous, which would require a large amount of point-measurements, but also because the surface heat fluxes do not only depend on the land cover type, but also on the soil moisture conditions, which can show a high spatial variability within the catchment (Samain et al., 2011). So an aggregation scheme for $<\mathrm{AE}>-$ calculation based on only point-measurements cannot be applied. The aggregation scheme based on local measurements of surface temperature, albedo and solar radiation proposed by Ezzahar et al. (2009) suffers from the same drawback due to the high level of heterogeneity of the Bellebeek catchment. Therefore, for this study, the results of the calibrated land surface model used by Samain et al. (2011) for evaluation of the representativeness of $\langle H\rangle$ for the catchment will be used here to convert point-measured values of $\mathrm{AE}$ to areaaveraged values for $<\mathrm{AE}>$. 

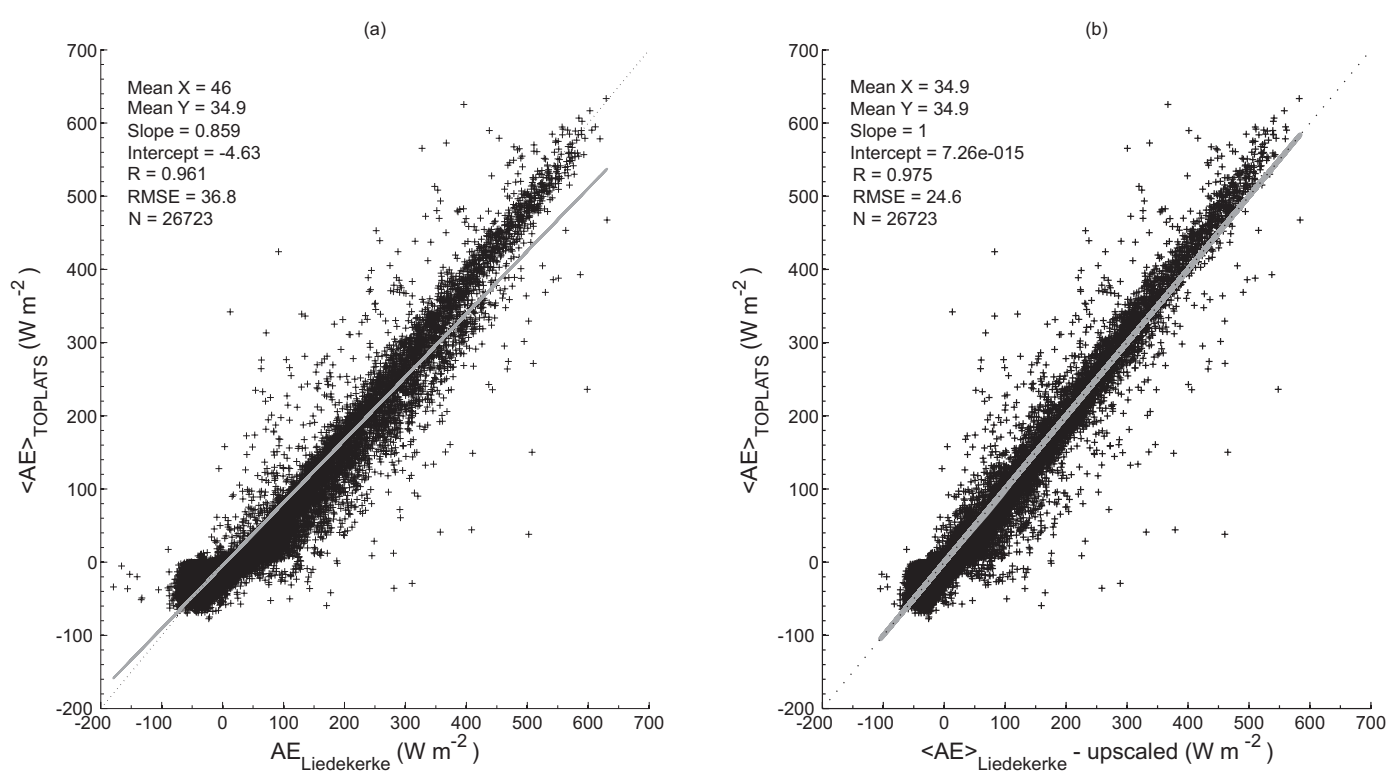

Fig. 2. Comparison between $\mathrm{AE}_{\text {Liedekerke and }<\mathrm{AE}>\text { TOPLATS }}$ (a) and comparison between upscaled values of $\mathrm{AE}_{\mathrm{Liedekerke}}$ for the catchment according to the monthly statistics as given in Table 2 (b).

\subsection{The hydrologic model (TOPLATS)}

The land-surface model used in this study is the TOPMODEL-Based Land-Atmosphere Transfer Scheme (TOPLATS) (Famiglietti and Wood, 1994), which is more extensively described in Samain et al. (2011). It is a physically based, spatially distributed land surface model that for every pixel within the catchment solves the surface energy balance equation through an iteration for the soil surface temperature.

As listed in Table 1, the TOPLATS model for the Bellebeek catchment uses a digital elevation model, soil texture and land cover maps and continuous meteorological observations which are considered to be representative for and uniformly distributed over the study area. In Samain et al. (2011), the land surface model has been calibrated and validated using discharge and energy balance terms at an hourly time step. TOPLATS has been calibrated for a period preceding the study period (from 1 August 2006 through $14 \mathrm{Au}-$ gust 2007) and validated from 15 August 2007 through 28 August 2009 (Samain et al., 2011). The considered period of this study is thus a part of the validation period. A good correspondence between observed and modeled discharge showed the accuracy of the model at the catchment scale. The accuracy of the model at the point scale was illustrated by the ability to simulate net radiation and soil heat flux at the pixel where BREB (Bowen Ratio Energy Balance)-stations were located, and latent and sensible heat flux from the source areas around the BREB-stations (Samain et al., 2011).

The model has further been used to evaluate the LAS measurement of the sensible heat flux over the LAS path with $H$ as modeled within the footprint and within the catchment.
For unstable conditions, it has been concluded that the LAS measurements of the sensible heat flux are representative for the catchment (Samain et al., 2011).

\subsection{From point-measured $\mathrm{AE}$ to catchment averaged $<\mathbf{A E}>$}

The objective of this study is to obtain $<\mathrm{LE}>$ in an operational way. Using the energy balance approach, this requires operational estimates of catchment-representative values of the available energy $<\mathrm{AE}>$, which are acquired from point-measurements and model results. At the meteorological station of Liedekerke, net radiation $\left(R_{\mathrm{n}, \text { Liedekerke }}\right)$ and soil heat flux $\left(G_{\text {Liedekerke}}\right)$ are continuously measured. From these data, point-values of $\mathrm{AE}$ can be calculated as $\mathrm{AE}_{\text {Liedekerke }}=R_{\mathrm{n}, \text { Liedekerke }}-G_{\text {Liedekerke }}$. Because areaaverage observations of net radiation and soil heat flux are not available, the catchment averaged available energy calculated with the TOPLATS-model for every pixel within the catchment $\left(<\mathrm{AE}>\right.$ TOPLATS $\left.=R_{\mathrm{n} \text {,TOPLATS }}-G_{\text {TOPLATS }}\right)$ is used to check the local measurements of $\mathrm{AE}_{\text {Liedekerke }}$ for the catchment. For the period from 1 January 2008 through 8 April 2011, the hourly values of $<\mathrm{AE}>$ TOPLATS are compared to the ground-based measurements of $\mathrm{AE}_{\text {Liedekerke }}$ in Fig. 2a. The mean monthly values of $\mathrm{AE}_{\text {Liedekerke }}$ and $<\mathrm{AE}>$ TOPLATS are given in Table 2. From this figure and table, it can be concluded that the point-measurements of $\mathrm{AE}$ overestimate the catchment averaged $<\mathrm{AE}>$. Because the linear regression with a correlation coefficient $R$ of 0.96 shows a good correspondence between both AE-values, but an overestimate of $\langle\mathrm{AE}\rangle$ by the Liedekerke pointmeasurements (slope of 0.86 ), a simple regression could 
Table 2. Statistics of the comparison between $\mathrm{AE}_{\text {Liedekerke }}$ and $<\mathrm{AE}>$ TOPLATS per month. Units are in $\mathrm{W} \mathrm{m}^{-2}$.

\begin{tabular}{lrrlrlll}
\hline Month & $\mathrm{AE}_{\text {Liedekerke }}$ & $\langle$ AE $>$ TOPLATS & slope & intercept & $R$ & RMSE & $N$ \\
\hline Jan & -2.75 & -12.05 & 0.32 & -11.16 & 0.67 & 29.35 & 2228 \\
Feb & 7.01 & -6.73 & 0.48 & -10.09 & 0.85 & 34.4 & 2206 \\
Mar & 33.68 & 17.25 & 0.64 & -4.41 & 0.94 & 47.57 & 2966 \\
Apr & 68.23 & 54.27 & 0.74 & 3.95 & 0.98 & 46.03 & 2290 \\
May & 93.44 & 84.22 & 0.9 & -0.29 & 0.98 & 33.7 & 2224 \\
Jun & 108.8 & 101.21 & 0.91 & 1.94 & 0.95 & 53.65 & 1640 \\
Jul & 105.82 & 99.52 & 0.92 & 1.9 & 0.97 & 39.73 & 2185 \\
Aug & 88.19 & 80.78 & 0.93 & -1.14 & 0.99 & 25.35 & 2226 \\
Sep & 53.2 & 43.6 & 0.89 & -3.67 & 0.98 & 26.18 & 2155 \\
Oct & 21.72 & 10.27 & 0.63 & -3.44 & 0.94 & 35.36 & 2226 \\
Nov & -0.93 & -16.34 & 0.43 & -15.94 & 0.78 & 31.16 & 2155 \\
Dec & -5 & -15.2 & 0.24 & -13.98 & 0.52 & 27.22 & 2222 \\
\hline
\end{tabular}

be applied for the conversion of $\mathrm{AE}_{\text {Liedekerke }}$ to $<\mathrm{AE}>-$ values. Nevertheless, from regressions taken per month (Table 2), it seems that there is an annual pattern in the regression slopes. This can be explained by the fact that the point-measurements are taken on a grass field where vegetation does not change much throughout the year, while the model results are an average for the entire catchment where the vegetation is changing throughout the year as, e.g. crops are sown, grow and harvested again, resulting in a different radiation budget. In order to take into account this dynamic character of the catchment, the parameters of the monthly regressions (Table 2) are used to convert the point measurements of $\mathrm{AE}_{\text {Liedekerke }}$ into $<\mathrm{AE}>$ TOPLATS-values, which can be considered as catchment averaged values of $<\mathrm{AE}>$. The converted values of $<\mathrm{AE}>$ from the pointmeasured $\mathrm{AE}_{\text {Liedekerke }}$ values are shown in Fig. $2 \mathrm{~b}$ where the slope of 1 and the $R$ of 0.975 illustrate that the adjusted values of $<\mathrm{AE}_{\text {Liedekerke,upscaled }}>$ are now more representative for the catchment.

\section{$3.3<\mathrm{LE}>$ from $<\mathrm{AE}>$ and $<H>$}

Because the point-measurements of $\mathrm{AE}_{\text {Liedekerke }}$ can be considered as being operationally available because they are retrieved from a permanent meteorological station, the above regression approach would allow to continuously and operationally calculate catchment averaged values of $\langle\mathrm{AE}\rangle$, which can be used for continuously calculating the catchment averaged latent heat flux $<\mathrm{LE}>$ using the energy balance equation and values of $\langle H\rangle$ as retrieved from the LAS. For the hourly time steps where LAS-data are available and $<H>$ could be calculated according to the principles explained by Samain et al. (2012) in order to become a continuous series of $\langle H>$ (stable and unstable conditions), $<\mathrm{LE}>$ is calculated as $\langle\mathrm{AE}\rangle-\langle H\rangle$. These values of $<\mathrm{LE}\rangle$ can then be compared to results of the remote sensing model ETLook.

\section{$4<$ LE > from ETLook}

As explained earlier, it is infeasible to evaluate area-averaged values of $<\mathrm{LE}>$ for the heterogeneous Bellebeek catchment with a weighted average of ground-based LE-measurements. Therefore, the remote sensing-based algorithm ETLook is used to intercompare $<\mathrm{LE}>$ for a limited time period. ETLook is an algorithm to compute evapotranspiration based on remote sensing data (Pelgrum et al., 2010). ETLook has been developed in addition to the SEBAL model (Bastiaanssen et al., 1998). A schematic overview of the different input parameters and intermediate products of the ETLook algorithm is illustrated in Fig. 3. Being mainly driven by actual soil moisture instead of surface temperature, usage of ETLook avoids the limiting factors of models based on closure of the energy balance. These include poor suitability of the models in larger areas, where differences in surface temperature cannot be solely explained by differences in the surface energy balance. Also, ETLook does not rely on thermal infrared sensors sensitive to cloudy conditions, which is a particular advantage in regions with a temperate climate. The model has been tested for different climatological conditions and locations around the world (Pelgrum et al., 2010).

ETLook distributes incoming solar radiation over canopy and soil within a pixel based on satellite-derived Leaf Area Index (LAI) values. The Penman-Monteith equation is solved separately for vegetation and soil in order to split the evapotranspiration (ET) into transpiration $(T)$ and evaporation $(E)$ :

$$
\begin{gathered}
T=\frac{\Delta\left(R_{\mathrm{n}, \text { canopy }}\right)+\rho c_{p} \frac{\Delta_{e}}{r_{\mathrm{a}, \text { canopy }}}}{\Delta+\gamma\left(1+\frac{r_{\text {canopy }}}{r_{\mathrm{a}, \text { canopy }}}\right)} \\
E=\frac{\Delta\left(R_{\mathrm{n}, \text { soil }}-G\right)+\rho c_{p} \frac{\Delta_{e}}{r_{\mathrm{a}, \text { soil }}}}{\Delta+\gamma\left(1+\frac{r_{\text {soil }}}{r_{\mathrm{a}, \text { soil }}}\right)},
\end{gathered}
$$

where $\Delta$ is the slope of the saturation vapour pressure curve $\left(\mathrm{hPa} \mathrm{K}^{-1}\right), \Delta_{e}$ is the vapor pressure deficit $(\mathrm{hPa}), \rho$ 


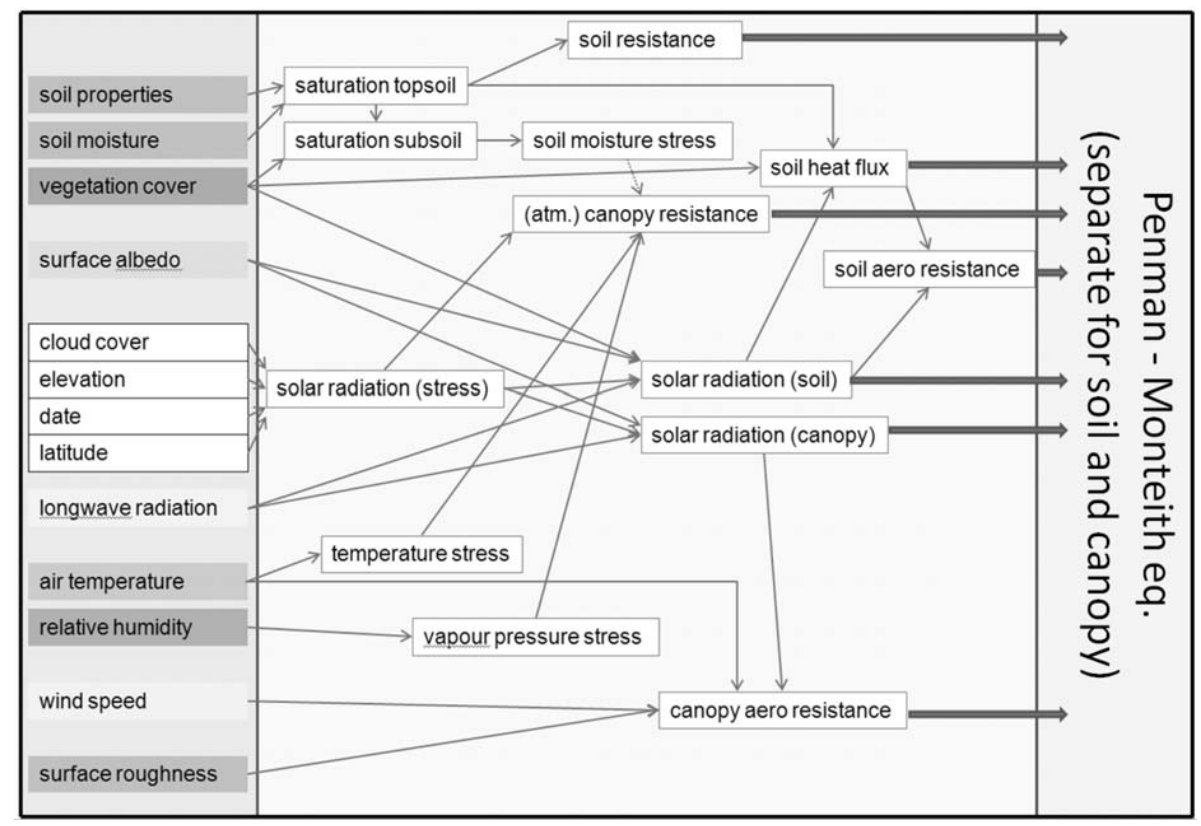

Fig. 3. Schematic flowchart of ETLook.

is the air density $\left(\mathrm{kg} \mathrm{m}^{-3}\right), c_{p}$ is the specific heat of dry air $\left(\mathrm{J} \mathrm{kg}^{-1} \mathrm{~K}^{-1}\right), \gamma$ is the psychrometric constant $\left(\mathrm{hPa} \mathrm{K}^{-1}\right), G$ is the soil heat flux $\left(\mathrm{W} \mathrm{m}^{-2}\right), R_{\mathrm{n} \text {,canopy }}$ and $R_{\mathrm{n}, \text { soil }}\left(\mathrm{W} \mathrm{m}^{-2}\right)$ are the net radiation for canopy and soil respectively, $r_{\text {canopy }}$ and $r_{\text {soil }}\left(\mathrm{s} \mathrm{m}^{-1}\right)$ are the canopy and soil resistance respectively, and $r_{\mathrm{a}, \text { canopy }}$ and $r_{\mathrm{a} \text {,soil }}\left(\mathrm{s} \mathrm{m}^{-1}\right)$ are the aerodynamic canopy and soil resistance respectively.

Daily $R_{\mathrm{n}}$ is computed by correcting solar radiation at the top of the atmosphere for atmospheric influences and surface albedo, and adding the occurring upward and downward longwave radiation. The LAI is then used to partition net radiation between canopy $R_{\mathrm{n} \text {,canopy }}$ and soil $R_{\mathrm{n} \text {,soil }}$. The aerodynamic canopy and soil resistance, $r_{\mathrm{a}, \text { canopy }}$ and $r_{\mathrm{a}, \text { soil }}$, are a function of wind speed and surface roughness. The soil resistance $r_{\text {soil }}$ is a function of the soil moisture content in the top soil: with less moisture in the top soil, the resistance to evaporation will increase. Soil moisture can be derived from remote sensing observations (such as AMSR-E microwave measurements). The canopy resistance $r_{\text {canopy }}$ is a function of the LAI and four dimensionless stress functions, which are dependent on soil moisture content and meteorological conditions.

The ETLook model for the Bellebeek catchment has a spatial resolution of $30 \mathrm{~m}$ and is run with time steps of one day. All inputs and outputs are daily values and Eqs. (1) and (2) are solved once for every day.

As summarized in Table 1, the model is based on the following input data. Firstly, daily spatial information on surface albedo and Normalized Difference Vegetation Index (NDVI) were obtained from remote sensing imagery from satellites as DMC (Disaster Monitoring Constellation),
Landsat and ASTER (Advanced Spaceborne Thermal Emission and Reflection Radiometer). Secondly, meteorological data like air temperature, wind speed, relative humidity and precipitaton are used from the meteorological station of Liedekerke, which are assumed to be representative for the entire Bellebeek catchment. The hourly data are averaged to a daily time step. Thirdly, atmospheric transmissivity was calculated from the Meteosat Second Generation (MSG) 30-min interval incoming short wave radiation product (provided by the Land Surface Analysis Satellite Applications Facility http://landsaf.meteo.pt). For the period and region of interest, MSG transmissivity data were available on a daily basis with a spatial resolution of approximately $6 \mathrm{~km}$. Next, because surface roughness affects the surface energy balance by influencing wind speed, an estimate of the surface roughness is made. Surface roughness is computed based on the terrain slope and the obstacle height that is assumed to be associated with a certain type of land cover. Land cover information acquired from the Corine dataset provided by the European Environment Agency is used. Since land cover is not constant over time due to a varying canopy height, LAI is used to correct for this based on the daily NDVI data (Bastiaanssen et al., 1998). Finally, the soil moisture is calculated based on an empirical relation between the actual top soil moisture and the weighted precipitation surplus of the preceeding fourteen days. This relation was determined during the calibration procedure of ETLook, which was performed using SEBAL simulations and water balance records for the year 2010 in The Netherlands. Tuning of the relation between precipitation and soil moisture deficit was a part of this calibration. The validity of such a relation is enhanced by the 
non-irrigated conditions in both the calibration area and the current study area.

The ETLook algorithm has been trained using water balance data and SEBAL simulations for the year 2010 in The Netherlands. Given the similar climatological and geographical conditions, this model configuration was assumed applicable for the study area currently under consideration. The ETLook algorithm is applied for the Bellebeek catchment for a six-month period: from 1 April 2009 through 30 September 2009. No ETLook results are available for 4 April 2009 because no meteorological data from the Liedekerke station were available that day. ETLook produces spatial information on $R_{\mathrm{n}}, G$, LE and $H\left(\mathrm{~W} \mathrm{~m}^{-2}\right)$ on a daily basis. It is clear that for the estimation of the surface fluxes, the ETlook approach is based on different input data compared to the LAS-approach. As such, the consistency between ETLookand LAS-derived fluxes can be analysed.

\section{Results and discussion}

\subsection{Performance of ETLook}

Before evaluating the consistency between LAS-derived $<$ LE $>$ and ETLook-derived $<$ LE $>$, the consistency of the output of the ETLook algorithm is analysed on the point scale and on the catchment scale with, respectively, measurements of the Eddy Covariance station in Ternat and TOPLATS model results of the catchment.

For the consistency analysis at the point scale, the calculated fluxes from the pixel where the EC-station is situated are extracted from the ETLook grids and compared to daily averages of the EC-measurements. A valid value for a daily average is only considered when all 24 hourly data (out of $24 \mathrm{~h}$ ) are available. Scatter plots of this comparison for daily available energy $\left(R_{\mathrm{n}}-G\right), H$ and LE are shown in Fig. 4a-c, respectively.

From Fig. 4a, it is clear that ETLook succeeds rather well in estimating the available energy at the point-scale (slope $=0.909$ and determination coefficient $R=0.934$ ). The ETLook estimated sensible and latent heat fluxes do reasonably agree with the EC-measurements. However, there is some mismatch ( $R=0.653$ and 0.625 for $H$ and LE respectively) which, e.g. can be due to a footprint issue, because the source area of the EC-measurement exceeds the $30 \mathrm{~m}$ resolution of ETLook (Samain et al., 2011). Apart from this explanation, it is probably mainly caused by the energy balance closure problem of the EC-technique. From the mean values of $H$ and LE, it can be seen that ETLook estimates both fluxes to be higher than measured with the EC-equipment. On the extra scatterplot in Fig. 4a, the sum of $H$ and LE measured with the EC-station is plotted against the available energy measured at the Ternat station. From the mean values and the slope of 0.814 , it is clear that for most of the daily time steps, $H+\mathrm{LE}$ is less than $R_{\mathrm{n}}-G$, which means that the
Table 3. Evapotranspiration sums for every 10-day period in the considered six-months period from estimates by ETLook, TOPLATS and LAS. The number of considered days within the 10day period is indicated by $N$.

\begin{tabular}{|c|c|c|c|c|c|c|}
\hline year & month & $\begin{array}{r}\text { Days for } \\
10 \text {-day } \\
\text { period }\end{array}$ & $\begin{array}{c}N \\
\text { (days) }\end{array}$ & $\begin{array}{r}\text { ETLook } \\
(\mathrm{mm})\end{array}$ & $\begin{array}{r}\text { TOPLATS } \\
(\mathrm{mm})\end{array}$ & $\begin{array}{r}\text { LAS } \\
(\mathrm{mm})\end{array}$ \\
\hline \multirow[t]{3}{*}{2009} & \multirow[t]{3}{*}{ April } & $1-10$ & 3 & 4.78 & 3.88 & 2.96 \\
\hline & & $11-20$ & 3 & 6.12 & 4.92 & 2.63 \\
\hline & & $21-30$ & 5 & 8.02 & 8.29 & 4.72 \\
\hline & \multirow[t]{3}{*}{ May } & $1-10$ & 8 & 12.78 & 15.98 & 12.09 \\
\hline & & $11-20$ & 8 & 13.67 & 16.70 & 13.48 \\
\hline & & $21-31$ & 8 & 21.41 & 23.91 & 20.09 \\
\hline & \multirow[t]{3}{*}{ June } & $1-10$ & 8 & 16.52 & 19.13 & 15.54 \\
\hline & & $11-20$ & 0 & - & - & 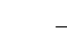 \\
\hline & & $21-30$ & 0 & - & - & - \\
\hline & \multirow[t]{3}{*}{ July } & $1-10$ & 7 & 14.93 & 17.98 & 14.96 \\
\hline & & $11-20$ & 4 & 10.11 & 11.28 & 12.03 \\
\hline & & $21-31$ & 8 & 24.53 & 22.89 & 23.28 \\
\hline & \multirow[t]{3}{*}{ Aug } & $1-10$ & 6 & 19.10 & 18.43 & 18.70 \\
\hline & & $11-20$ & 5 & 12.07 & 12.71 & 12.73 \\
\hline & & $21-31$ & 9 & 22.17 & 20.23 & 17.21 \\
\hline & \multirow[t]{3}{*}{ Sep } & $1-10$ & 10 & 17.28 & 16.74 & 12.37 \\
\hline & & $11-20$ & 4 & 5.78 & 4.25 & 3.02 \\
\hline & & $21-30$ & 3 & 3.56 & 2.90 & 0.77 \\
\hline
\end{tabular}

measurements from the EC-station show an unclosed energybalance, a problem that has been described extensively. According to Foken (2008), the energy balance closure problem of EC-measurements is not a problem of measurement errors or storage terms, but a scale problem as EC equipment is not able to measure the exchange processes on the larger scale and, as such, does not measure large scale fluxes that also need to be accounted for in the energy balance at the point scale.

At the catchment scale, the average of the fluxes calculated by ETLook for all pixels within the catchment are compared to the catchment averaged fluxes calculated by TOPLATS and averaged to a daily time step. Scatterplots for $<\mathrm{AE}\rangle$, $<\mathrm{LE}\rangle$ and $\langle H\rangle$ for daily time steps where all data are available are shown in Fig. $4 \mathrm{~d}-\mathrm{f}$ respectively. The daily time series as well as a plot of the cumulative fluxes for the available time steps in the considered 6 months period is shown in Fig. 5. In general, a small bias and small RMSE values for all the energy balance terms have been obtained. Furthermore, the high $R$-values and the fact that all slopes have a value of almost 0.9 indicate that ETLook and TOPLATS have comparable results for $\langle\mathrm{AE}\rangle,\langle H\rangle$ and $\langle\mathrm{LE}>$, and ETLook thus performs equally well as the spatially distributed hydrological model for the estimation of the catchment averaged fluxes on a daily basis. 


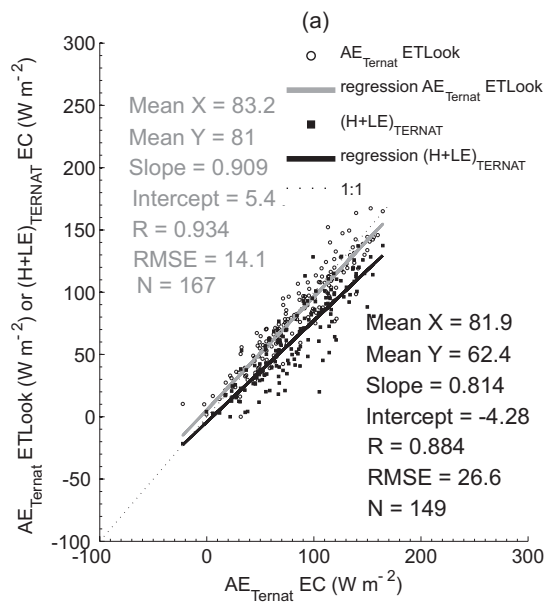

(d)

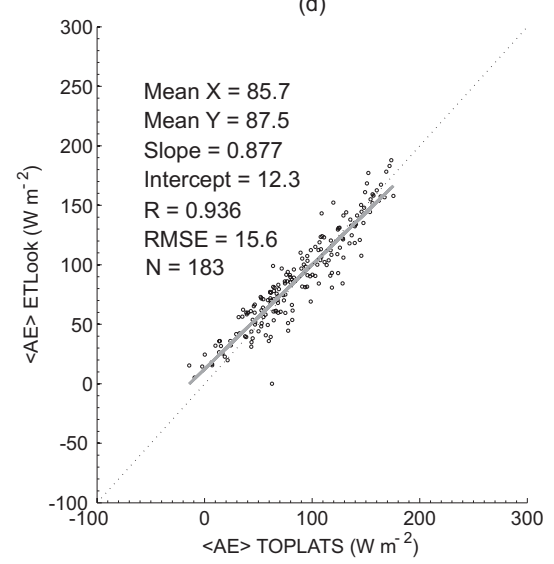

(b)

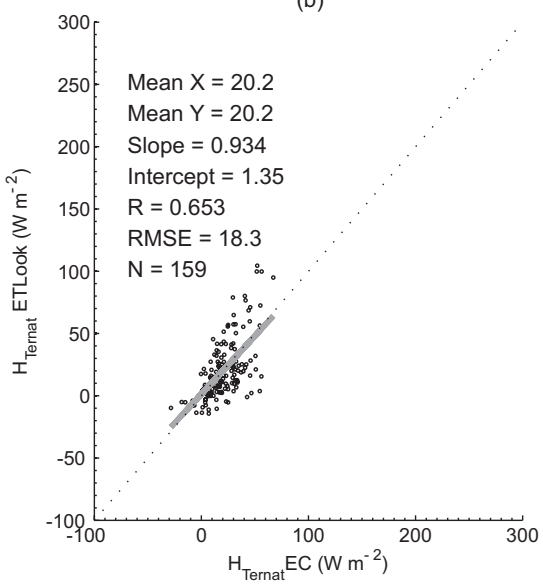

(e)

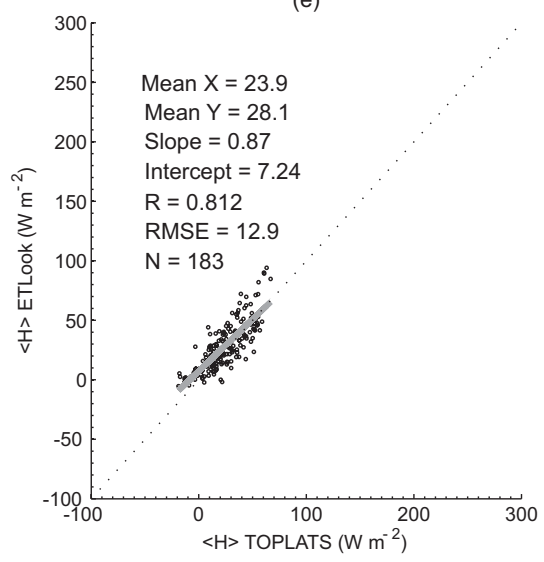

(c)

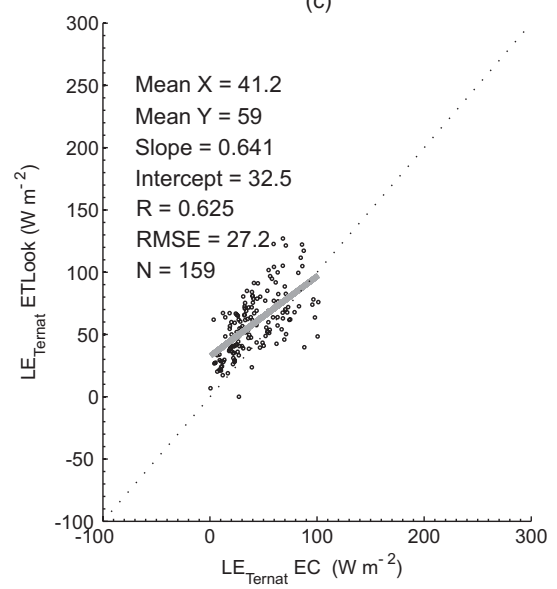

(f)

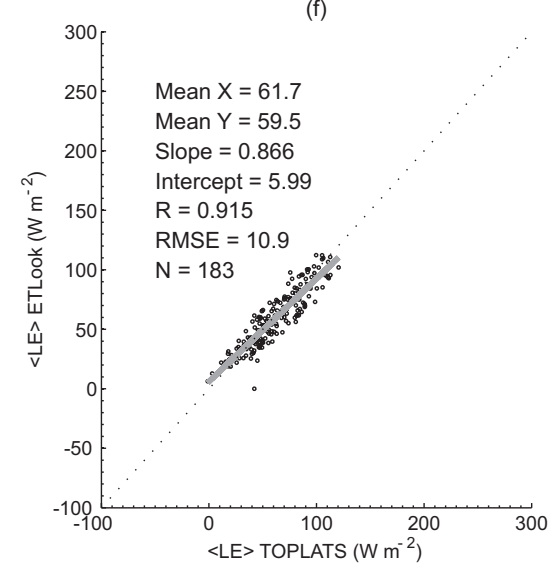

Fig. 4. Comparison for AE, $H$ and LE between ETLook and point-measurements (a), (b) and (c), and between ETLook and TOPLATS (d), (e) and (f).

\subsection{Consistency between LAS, ETLook and TOPLATS}

Because ETLook is able to estimate the energy balance terms at the point scale and at the catchment scale, it can be used as a consistency check for the latent heat flux (or evapotranspiration rates) estimated from the LAS. Samain et al. (2011) have shown that the sensible heat flux estimates from the LAS in unstable conditions are representative for the catchment.

To evaluate the consistency between LAS and remote sensing-based fluxes, the daily averages of the measured sensible heat flux by the LAS, the used values of available energy to convert LAS- $H$ into LE-values and the resulting latent heat flux from the energy balance equation are compared to the catchment-average of these daily fluxes $(<\mathrm{AE}>$, $<H>$ and $<\mathrm{LE}>$ ) calculated by ETLook. Scatterplots for all these components of the energy balance on the catchment scale are presented in Fig. $6 a-c$ respectively, while the time series are shown in Fig. 5.

The scatterplot and time series of $<\mathrm{AE}>$ reveal that the available energy for the catchment estimated from the
Liedekerke point-measurements but upscaled to the catchment through the use of the hydrologic model shows good correspondence with the catchment available energy calculated by ETLook $\left(\mathrm{RMSE}=14.2 \mathrm{~W} \mathrm{~m}^{-2}, R=0.93\right.$ and slope $=0.9$ ). This is comparable to the results of Teixeira et al. (2009) where an RMSE of $17.5 \mathrm{~W} \mathrm{~m}^{-2}$ and $R^{2}$ of 0.94 showed a good agreement between SEBAL results and field measurements.

As Samain et al. (2012) states that the daily average of $H$ derived from LAS-data can be largely influenced by a wrong estimate for $H$ during some hours of the day, valid daily averages of the LAS-derived fluxes are considered only where for all $24 \mathrm{~h}$ out of 24 hourly data are available to calculate $<H>$ and $<\mathrm{LE}>$. Because of the procedure for sensible heat flux calculation from LAS-data (Samain et al., 2012), there are a considerable amount of hours where no $\langle H\rangle$ (and resulting $<\mathrm{LE}>$ ) could be determined from LAS data, and hence less daily averages could be calculated than for $<\mathrm{AE}>$.

For the resulting days, the scatterplots of the daily averaged fluxes are given in Fig. $6 \mathrm{a}-\mathrm{c}$. The fluxes calculated with 

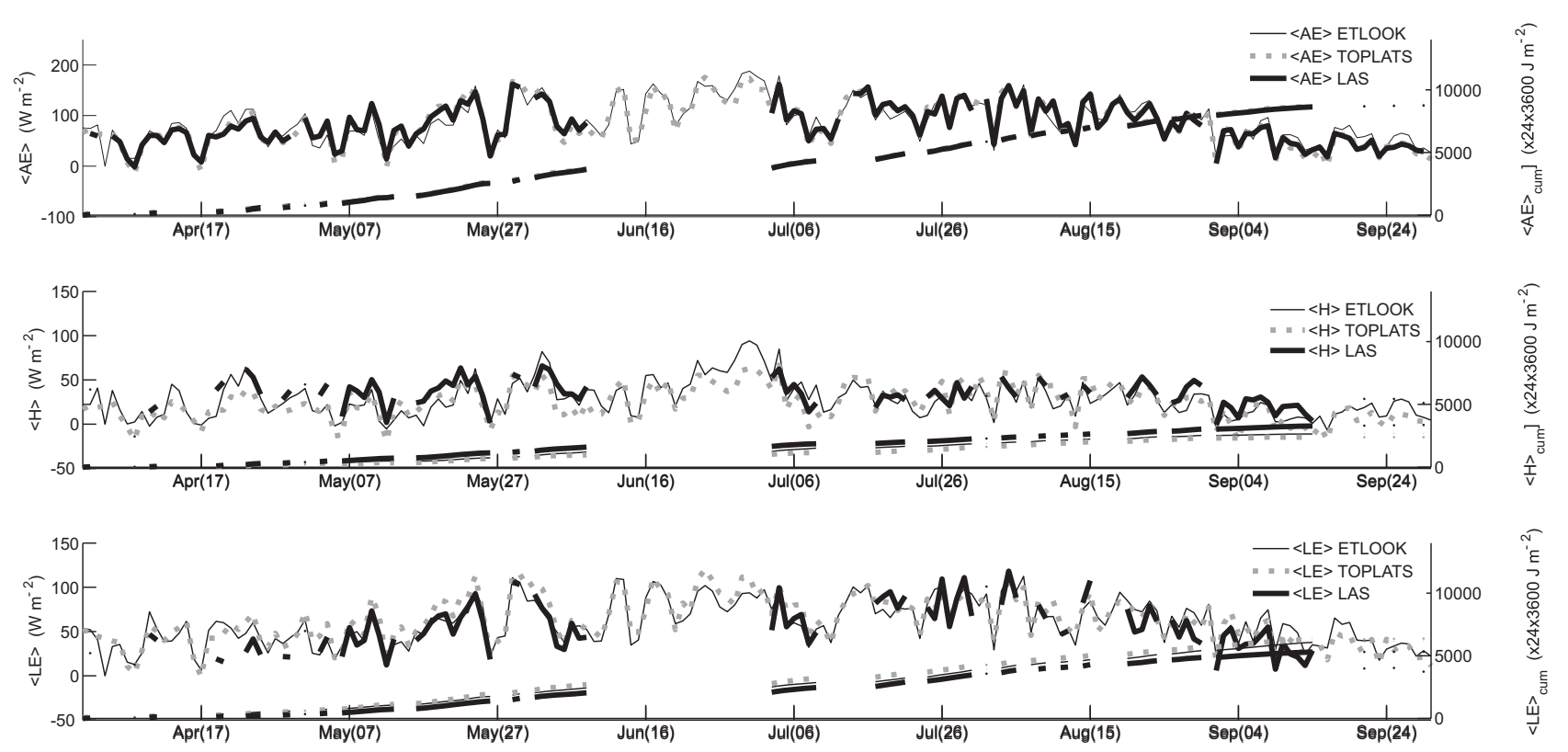

Fig. 5. Time series for daily $<\mathrm{AE}>$ (top panel), $<H>$ (middle panel) and $<$ LE $>$ (bottom panel) as calculated by ETLook, TOPLATS and LAS for the Bellebeek catchment. Cumulative values for the available days are given as well (right axes).
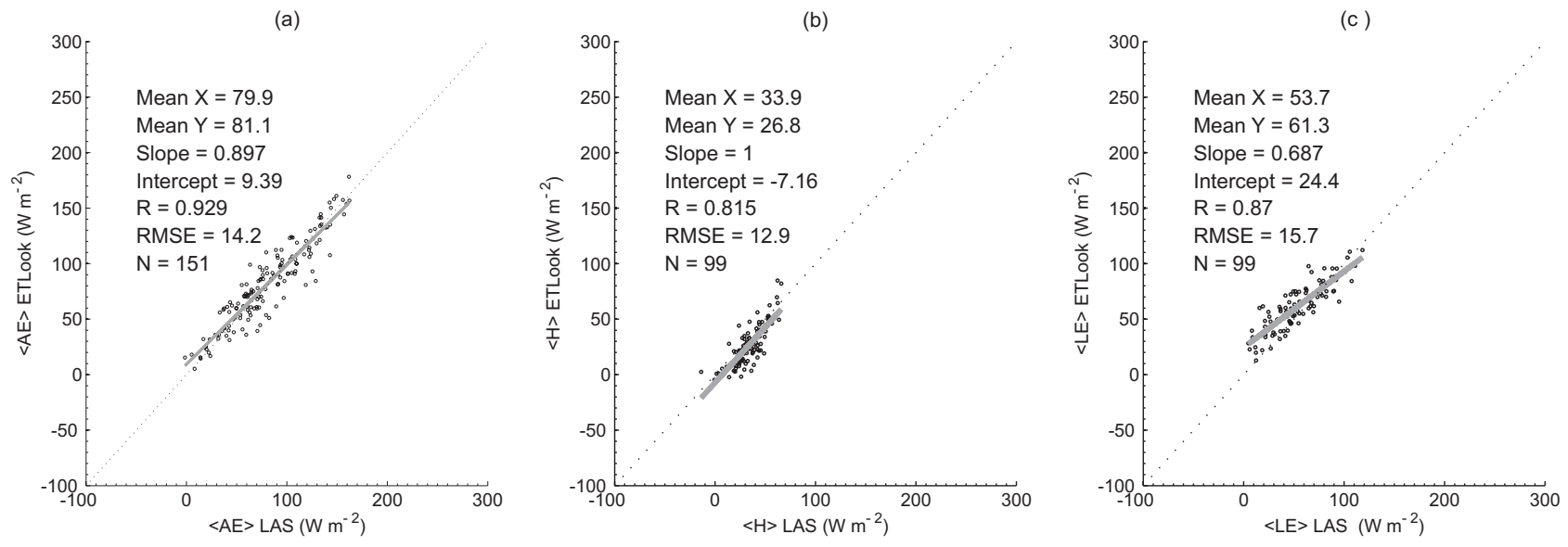

Fig. 6. Comparison for ETLook-derived and LAS-derived $<\mathrm{AE}>(\mathbf{a}),<H>$ (b) and $<\mathrm{LE}>$ (c).

ETLook and the estimated fluxes from LAS-data correlate rather well and are close to the expected 1:1 relation. From this comparison it can also be seen that LAS estimates the daily average of $\langle H\rangle$ on average slightly higher than ETLook, and as both estimates of $<\mathrm{LE}>$ are based on the energy balance equation, it is clear that the LAS-derived daily $<L E>$-fluxes are on average slightly lower than estimated by ETLook. However, the RMSE-values for daily $H$ and LE of respectively 12.9 and $15.7 \mathrm{~W} \mathrm{~m}^{-2}$ and $R$-values of 0.815 and 0.87 are also comparable to the results of Teixeira et al. (2009) where RMSE values of 41.8 and $33.8 \mathrm{~W} \mathrm{~m}^{-2}$ were found with $R^{2}$-values of 0.93 and 0.83 between SEBAL estimates and field measurements of $H$ and LE.
Because the main purpose of the LAS-installation is to provide estimates of catchment averaged actual evapotranspiration rates as input for a flood forecasting model for the Bellebeek catchment, the focus is on the resulting evapotranspiration rates as they will play an important role in the water balance and thus on the output of the flood forecasting model. In order to assess the influence on the water balance, for the overlapping days of the considered techniques (based on 24 hourly values), daily evapotranspiration rates (in $\mathrm{mm}$ ) are calculated from latent heat fluxes (in $\mathrm{W} \mathrm{m}^{-2}$ ) and summed per 10-day period (Table 3). Overall, the evapotranspiration rates from the three different techniques correlate very well. Looking in detail at the table shows that the slightly lower estimates for $<\mathrm{LE}>$ derived from LAS-data 
in comparison with ETLook appear in April and September. For those months, the resemblance between ETLookand TOPLATS-results is slightly better. For the other months there is no clear over- or underestimation of the 10-day evapotranspiration estimates by any of the three techniques used. For the 10-day periods from May to August, the average differences between LAS and ETLook and between LAS and TOPLATS are respectively $3.5 \%$ and $12.6 \%$, which is similar to the results of Hemakumara et al. (2003) where the deviation of 10-days ET between LAS and SEBAL was averagely $17 \%$.

Samain et al. (2011) mentioned an underestimate of $<H>$ measured with the LAS compared to the TOPLATS results. Different possible explanations for this underestimation of $\langle H\rangle$ have been mentioned, such as the saturation effect, flux divergence and/or uncertainty of the stability functions. This underestimate of $\langle H\rangle$ would result in an overestimate of LAS-derived $<$ LE $>$ compared to TOPLATS. However, from the 10-day evapotranspiration rates, this overestimate of $<\mathrm{LE}>$ by LAS compared to TOPLATS is not clear for the considered period in this study. Probably a better judgement of stable and unstable conditions for the LAS (as elaborated in Samain et al., 2012) or the model parameters for TOPLATS are an explanation for the better agreement between TOPLATS and LAS for the considered period.

\section{Summary and conclusions}

In this paper, daily estimates of the evapotranspiration rates for a heterogeneous catchment of $102.3 \mathrm{~km}^{2}$ from three different techniques have been made and intercompared.

Firstly, the catchment averaged evapotranspiration rates are estimated from the energy balance approach based on LAS-measurements of $H$ over a $9.5 \mathrm{~km}$ path within the catchment and estimates of the available energy for the catchment. Operational estimates of the catchment available energy are calculated from point measurements of $R_{\mathrm{n}}$ and $G$ in the catchment and adjusted to the catchment scale through the use of the calibrated land surface model TOPLATS.

Secondly, ETLook is introduced as a remote sensing tool to estimate continuous series of the energy balance terms for large areas and for high temporal resolutions (up to daily time step) without the restriction of cloud free conditions. As such, ETLook provides the opportunity of a consistency analysis for the large-scale estimates of the sensible and latent heat flux from the LAS. Therefore, in first instance, the performance of ETLook at the point and at the catchment scale is evaluated by comparing the ETLook-results to daily averages of $\mathrm{AE}, H$ and LE from an EC-station in the catchment and to TOPLATS model results for the catchment.

Because it seems that ETLook is able to estimate the energy balance terms for daily time steps at the point scale and at the catchment scale, it is used to intercompare the latent heat flux (or evapotranspiration rates) estimated from the LAS and TOPLATS on a daily basis. As for the available energy, ETLook and the estimates from the Liedekerke point-measurements adjusted to the catchment scale through the use of the hydrologic model show good correspondence with an RMSE of $14.2 \mathrm{~W} \mathrm{~m}^{-2}$ and $R$-value of 0.929 . For the sensible and latent heat fluxes, daily averages from LAS and ETLook-results are also in good agreement (RMSE of 12.9 and $\left.15.7 \mathrm{~W} \mathrm{~m}^{-2}\right)$, but with some more bias $(R=0.815$ and 0.87 ). Also, from the evapotranspiration rates calculated per 10-day period, there is a good correspondence between TOPLATS-results and both ETLook and LAS-derived evapotranspiration rates with average differences from $12.6 \%$ to $3.5 \%$.

To conclude, ETLook provides the opportunity to estimate continuous series of the energy balance terms of a large area such as a catchment for daily time steps. However, as flood forecast models usually work at a higher temporal resolution (hours), ETLook is less suitable to produce (hourly) catchment averaged evapotranspiration estimates. Because a LAS works at a much higher temporal resolution (minute), it is more suitable to provide hourly estimates of catchment averaged evapotranspiration rates. The evapotranspiration rates can be estimated from sensible heat flux estimates by the LAS using the energy balance approach when representative estimates of the available energy for the catchment can be determined. Another restriction in the use of the LAS is the fact that stability conditions have to be determined and that no fluxes can be calculated for conditions where the LAS-signal is disturbed, e.g. by precipitation or fog. Nevertheless, from the intercomparison of both the ETLook and TOPLATS-results, it seems that despite these limitations, for hours where LAS data are available, the LAS can provide good estimates of the evapotranspiration rates at a high temporal resolution.

Acknowledgements. The authors would like to express their gratitude to the Department Operational Water Management of the Ministery of the Flemish Community for providing the meteorological, and scintillometer data and to the Flanders Geographical Information Agency for providing the soil texture, land use and DEM maps. We would also like to thank A. Van der Hasselt for the kind offer to install the EC-station on his property in Ternat. A special thanks to Davy Loete from the Laboratory of Hydrology and Water Management of Ghent University for his help in the installation and maintenance of the EC-station. We would also like to thank the Foundation for Scientific Research of the Flemisch Community (FWO-Vlaanderen) for their funding of the EC equipment, and Henk De Bruin, Volker Thiermann and Bettina Schrauf for the information and support on scintillometer measurements and treatment.

Edited by: A. Loew 


\section{References}

Bai, J., Liu, S., and Mao, D.: Area-averaged Evapotranspiration Fluxes Measured from Large Aperture Scintillometer in the Hai River Basin, in: River Basin Research And Planning Approach, edited by: Zhang, H., Zhao, R., and Zhoa, H., Orient ACAD Forum, Marrickville, Australia, 331-340, 2009.

Bastiaanssen, W., Menenti, M., Feddes, R., and Holtslag, A.: A remote sensing surface energy balance algorithm for land (SEBAL), J. Hydrol., 213, 198-212, 1998.

Ezzahar, J. and Chehbouni, A.: The use of scintillometry for validating aggregation schemes over heterogeneous grids, Agr. Forest Meteorol., 149, 2098-2109, doi:10.1016/j.agrformet.2009.09.004, 2009.

Ezzahar, J., Chehbouni, A., Hoedjes, J., Ramier, D., Boulain, N., Boubkraoui, S., Cappelaere, B., Descroix, L., Mougenot, B., and Timouk, F.: Combining scintillometer measurements and an aggregation scheme to estimate area-averaged latent heat flux during the AMMA experiment, J. Hydrol., 375, 217-226, 2009.

Famiglietti, J. S. and Wood, E. F.: Multiscale modeling of spatially variable water and energy balance processes, Water Resour. Res., 30, 3061-3078, 1994.

Foken, T.: The energy balance closure problem: An overview, Ecol. Appl., 18, 1351-1367, doi:10.1890/06-0922.1, 2008.

Guyot, A., Cohard, J.-M., Anquetin, S., Galle, S., and Lloyd, C.: Combined analysis of energy and water balances to estimate latent heat flux of a sudanian small catchment, J. Hydrol., 375, 227-240, 2009.

Hartogensis, O., Watts, C., Rodriquez, J.-C., and De Bruin, H. A. R.: Derivation of an effective height for scintillometers: La Poza experiment in Northwest Mexico, J. Hydrometeorol., 4, 915-928, 2003.

Hemakumara, H., Chandrapala, L., and Moene, A.: Evapotranspiration fluxes over mixed vegetation areas measured from large aperture scintillometer, Agr. Water Manage., 58, 109-122, 2003.

Kleissl, J., Gomez, J., Hong, S. H., Hendrickx, J. M. H., Rahn, T., and Defoor, W. L.: Large aperture scintillometer intercomparison study, Bound.-Lay. Meteorol., 128, 133-150, 2008.

Kleissl, J., Hong, S.-H., and Hendrickx, J. M. H.: New Mexico Scintillometer Network. Supporting Remote Sensing and Hydrologic and Meteorological Models, B. Am. Meteorol. Soc., 90, 207218, doi:10.1175/2008BAMS2480.1, 2009a.

Kleissl, J., Watts, C. J., Rodriguez, J. C., Naif, S., and Vivoni, E. R.: Scintillometer Intercomparison Study-Continued, Bound.Lay. Meteorol., 130, 437-443, doi:10.1007/s10546-009-9352-z, 2009b.

Kohsiek, W., Meijninger, W. M. L., Debruin, H. A. R., and Beyrich, F.: Saturation of the large aperture scintillometer, Bound.-Lay. Meteorol., 121, 111-126, 2006.

Mauder, M. and Foken, T.: Documentation and instruction manual of the eddy covariance software package TK2, Univ. of Bayreuth, Dept. of Mikrometeorology, Bayreuth, Germany, 2004.
Mauder, M., Foken, T., Clement, R., Elbers, J. A., Eugster, W., Grünwald, T., Heusinkveld, B., and Kolle, O.: Quality control of CarboEurope flux data - Part 2: Inter-comparison of eddy-covariance software, Biogeosciences, 5, 451-462, doi:10.5194/bg-5-451-2008, 2008.

Meijninger, W., Hartogensis, O., Kohsiek, W., Hoedjes, J., Zuurbier, R., and De Bruin, H. A. R.: Determination of area-averaged sensible heat fluxes with a large aperture scintillometer over a heterogeneous surface - Flevoland field experiment, Bound.-Lay. Meteorol., 105, 37-62, 2002.

Meijninger, W. M. L., Beyrich, F., Luedi, A., Kohsiek, W., and De Bruin, H. A. R.: Scintillometer-based turbulent fluxes of sensible and latent heat over a heterogeneous land surface - A contribution to LITFASS-2003, Bound.-Lay. Meteorol., 121, 89110, 2006.

Pauwels, V. and Samson, R.: Comparison of different methods to measure and model actual evapotranspiration rates for a wet sloping grassland, Agr. Water Manage., 82, 1-24, 2006.

Pelgrum, H., Miltenburg, I., Cheema, M., Klaasse, A., and Bastiaanssen, W.: ETLook a Novel Continental Evapotranspiration Algorithm, in: Remote Sensing and Hydrology Symposium, Jackson Hole, Wyoming, USA, 2010.

Samain, B., Ferket, B., Defloor, W., and Pauwels, V.: Estimation of catchment averaged sensible heat fluxes using a Large Aperture Scintillometer, Water Resources Research, 47, W05536, doi:10.1029/2009WR009032, 2011.

Samain, B., Defloor, W., and Pauwels, V.: Continuous time series of catchment-averaged sensible heat flux from a Large Aperture Scintillometer: efficient estimation of stability conditions and importance of fluxes under stable conditions, J. Hydrometeorol., 13, 423-442, doi:10.1175/JHM-D-11-030.1, 2012.

Savage, M. J.: Estimation of evaporation using a dual-beam surface layer scintillometer and component energy balance measurements, Agr. Forest Meteorol., 149, 501-517, doi:10.1016/j.agrformet.2008.09.012, 2009.

Teixeira, A. H. D. C., Bastiaanssen, W. G. M., Ahmad, M. D., and Bos, M. G.: Reviewing SEBAL input parameters for assessing evapotranspiration and water productivity for the LowMiddle Sao Francisco River basin, Brazil Part A: Calibration and validation, Agr. Forest Meteorol., 149, 462-476, doi:10.1016/j.agrformet.2008.09.016, 2009.

Verstraeten, W. W., Veroustraete, F., and Feyen, J.: Assessment of evapotranspiration and soil moisture content across different scales of observation, Sensors, 8, 70-117, doi:10.3390/s8010070, 2008.

Webb, E., Pearman, G., and Leuning, R.: Correction of Flux Measurements for Density Effects due to Heat and Water Vapor Transfer, Q. J. Roy. Meteorol. Soc., 106, 85-100, 1980.

$\mathrm{Xu}, \mathrm{C}$. and Singh, V.: Evaluation of three complementary relationship evapotranspiration models by water balance approach to estimate actual regional evapotranspiration in different climatic regions, J. Hydrol., 308, 105-121, doi:10.1016/j.jhydrol.2004.10.024, 2005. 